\title{
Past, Present, Future: The Landscape as Design Collaborator
}

GABRIEL KAPRIELIAN

Temple University

The contemporary practice of designing the built environment is dominated by a top-down approach that imposes rules and boundaries from above, favoring grid-based geometries and hard edges, regardless of the latent potential in the landscape. By not working with the place-specific landscape in the design process, we have been altering the environment in uniformed ways that have led to generic urban form, ecological degradation, and cities that lack resilience and adaptability in the face of growing threats from climate change. We are unlikely to fix the problems of cities by using the same toolbox that got us there in the first place. It is time to define a new approach that begins with a knowledge of the landscape past, present, and future. This will be of particular importance at the edge of cities that mitigate the relationship between the "built" and "natural," especially coastal communities that are threatened by inundation from sea-level rise and storm events. By utilizing techniques in site analysis as a design driver, I propose that we reflect on past landscape conditions, urban transformations, and a layering of present environmental conditions to inform speculative future scenarios that lead to new relationships between urbanism and ecology.

\section{INTRODUCTION}

The current paradigm of urbanism has led to static cities that have often negated the importance of ecological conditions in the landscape that they are been built upon. This antiquated model of city building has sought to subjugate the landscape, while the technological advancements achieved since the industrial revolution have allowed us to radically transform the landscape, leading to the era of the Anthropocene. We now have an ethical obligation to design our cities to adapt to the changing environment so as not to pass on problems to future generations.

As we have seen in recent years, devastating storms in New Orleans, New York, and Houston have highlighted the inability of outdated city infrastructure to respond to major storm events. Each of these places also has something in common; they are all coastal cities that have been built on reclaimed land, negating the natural functions and mutability of the surrounding ecology. These coastal edge cities and many others across the country and around the world will need to adapt to the challenges presented by rising sea levels and climate change events.
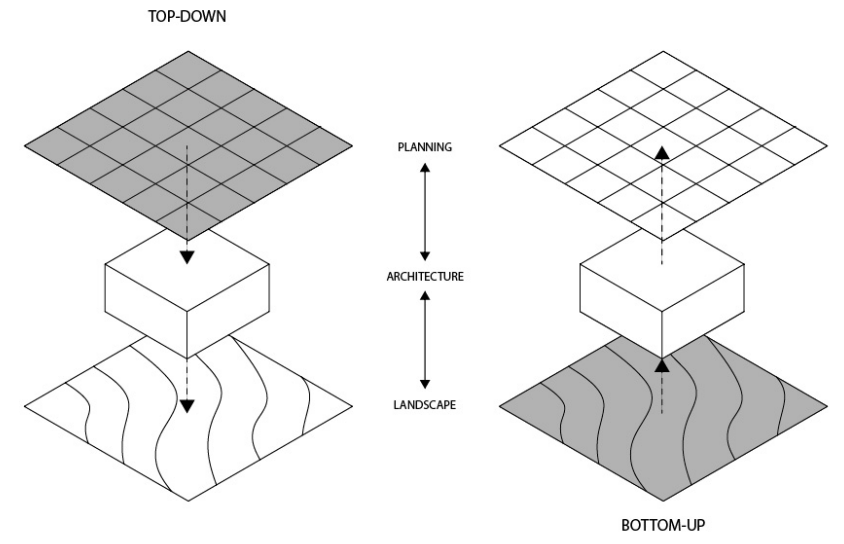

Figure 1: Diagram of Top-down vs. Bottom-up Approach to Design of the Environment.

My work specifically focuses on the urbanized shoreline of the San Francisco Bay Area. Over the years, the Bay Area has seen a large portion of the historic wetlands filled or leveed off for residential, commercial, and industrial land uses. With current sea-level rise projections, it appears that the water will once again reclaim the bay lands that have been filled, leading to complicated choices of whether to retreat, accommodate, or protect against flooding. To determine resilient strategies for sea-level rise adaptation, we must work with the landscape, past, present, and future, as a design collaborator.

In this paper, I will first discuss the ways in which we can collaborate with the landscape by utilizing site analysis techniques as a design driver. I will then examine the problem with defining the water's edge and how this can be an impediment to developing adaptable urban waterfronts. I will conclude with a brief description of how living shorelines can be designed in collaboration with a knowledge of the landscape to create resilient waterfronts that support coastal cohabitation of urban development and natural ecology.

\section{SITE ANALYSIS AS DESIGN DRIVER}

The model of top down planning for cities dictates a framework for architectural design that must fit into a pre-determined structural form that is often based on an abstract notion of space, rather than informed by the characteristics of the landscape. There is a desire for clear formal organization and continuity of the past in traditional planning that is aloof from the ground level and perceived human experience of place. Additionally, the problem of scale and definition of "site" remains one of the primary issues in the design of the built and 


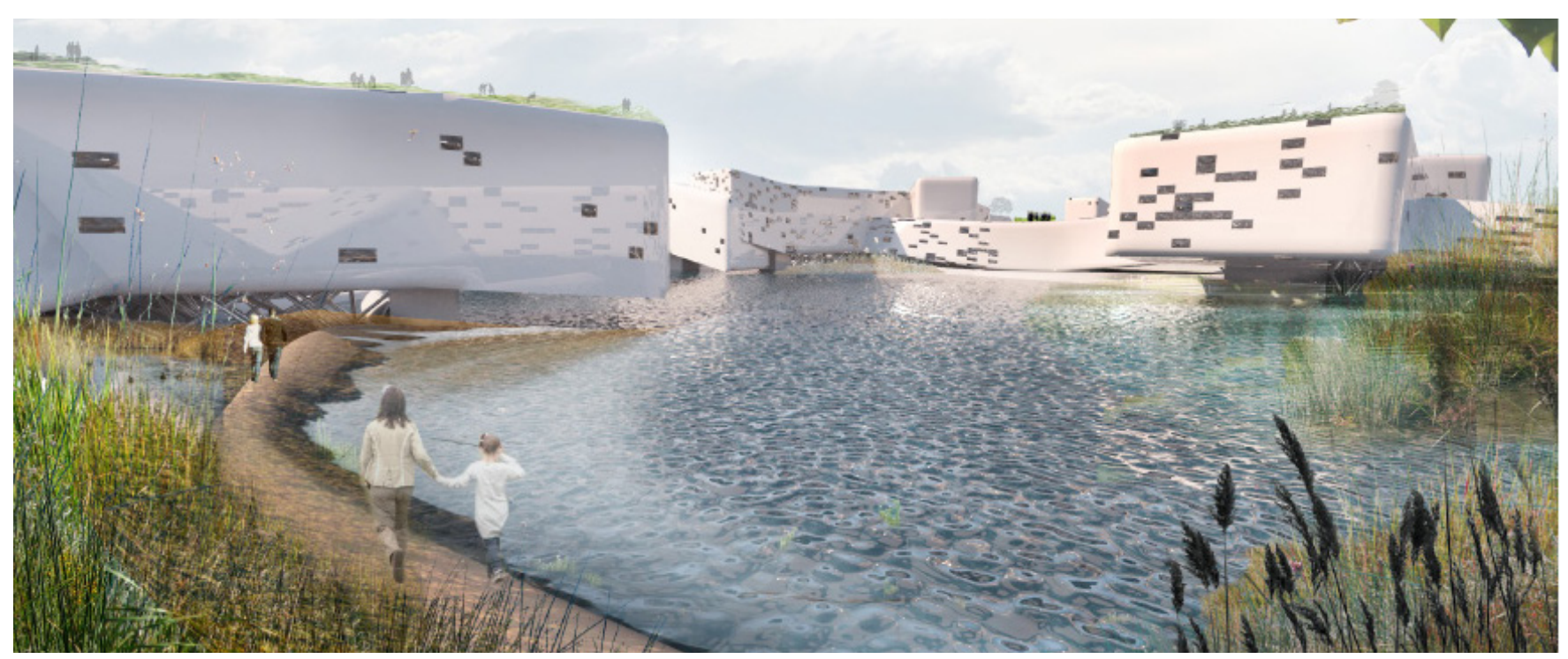

Figure 2: Visualization of Coastal Cohabitation with Sea-Level Rise (in collaboration with Carlos Sandoval)

natural environments. The landscape is continuous, whereas site boundaries and city edges attempt to define space in hardline conditions. Through site analysis, architecture has the ability to bridge these divides and connect landscape and infrastructure with human habitation.

If we settle on working with the landscape as a design collaborator, the question that arises is how? I propose expanding the scope of site analysis and approaching it as an integral part of the design process, one that involves active and subjective work through investigation and representation of contextual information, in addition to more conventional and scientific methods of traditional practice. I believe that this will provide an opportunity for architectural designs that are more connected with the site and whose form is developed in response to a narrative of place. By critically thinking about site analysis as a beginning phase of the design process, designers can better tackle complex relationships between the built and natural environment, observable and unseen factors, and social issues that more thoroughly place a design response within the continuum of history and culture imbedded in a site location.

Site is not easily defined in architecture, as it represents both a physical place and a conceptual construct. Site is never a blank canvas, but a rich tapestry of embedded knowledge and dormant potential. Site is more than constraints and opportunities from a suitability analysis. It is more than an analytical process of categorizing geological and climatic information, real estate value, or demographics. It is measurable and comprehensible only through analysis and representation of its parts. Sites incorporate multiple realities simultaneously and can be represented through diverse perspectives and subjective interpretations. Site analysis offers fertile ground for an engagement with the landscape in the architectural design process.

In Site Matter, Carol Burns and Andrea Kahn describe site thinking as "continually oscillating between material and conceptual, abstract and physical, discursive and experiential, and general and specific points of view." ${ }^{1}$ This varied and contradictory interpretation reconfigures site as a dynamic process and places it in a broader discourse. With both physical and conceptual identities, site offers to participate in a dialog with the designer. Site gains meaning through analysis and the designer gains knowledge through its representation. Andrea Kahn states that "ideas of site come through making. Designers confront the challenge of defining sites through a creative process of representation." ${ }^{2}$ It is precisely the process of discovery through site analysis and representation that I am most interested.

The work and writing of James Corner has brought site analysis into the foreground of the design process. Like Kahn, Corner has come to a similar conclusion in his essay on the "Agency of Mapping," where he states "... mapping is perhaps the most formative and creative act of any design process, first disclosing and then staging the conditions for the emergence of new realities."3 Mapping is a subcategory of site analysis that as Corner describes is itself a design process. Maps are able to layer information of the landscape to highlight areas of convergence; they can uncover unobservable site factors and visualize multiple time periods simultaneously.

Layering geo-referenced information of the site past, present, and potential future reveal the hidden potential of the landscape to inform design. Since most urbanized development takes place on a constructed landscape it can be difficult to determine the past landscape and the process of its evolution over time. However, by examining the pre-development ground through techniques in historical ecology we can 
Historic
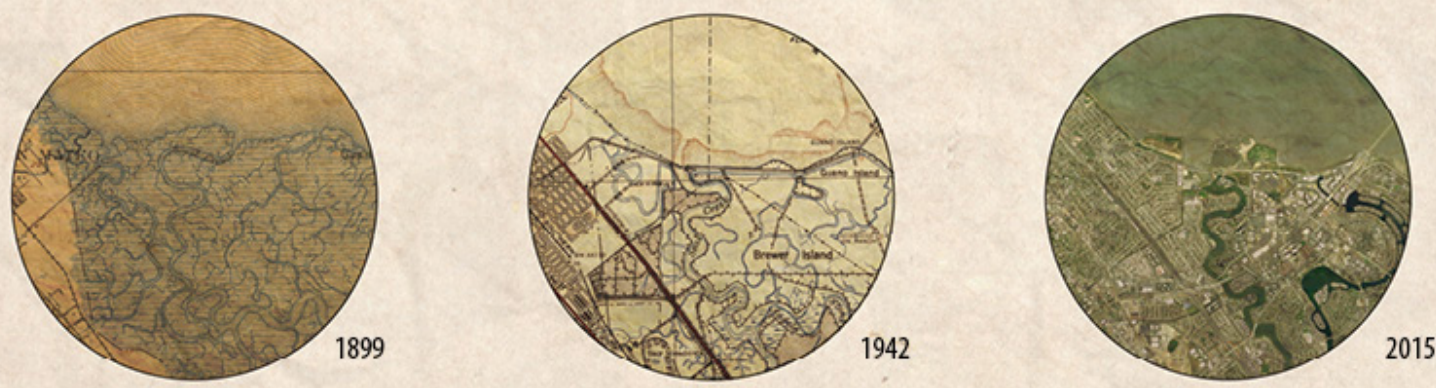

Sea-Level Rise
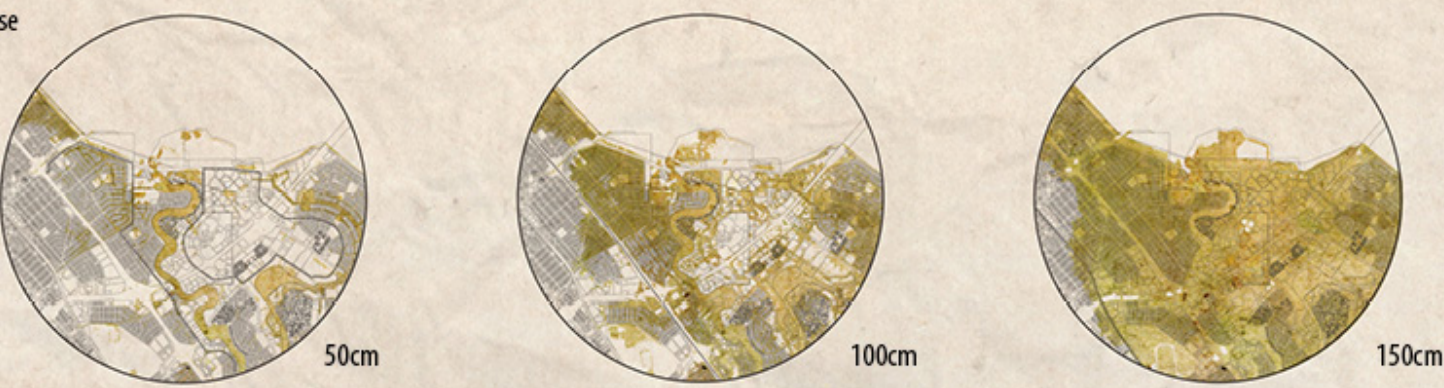

Wetlands
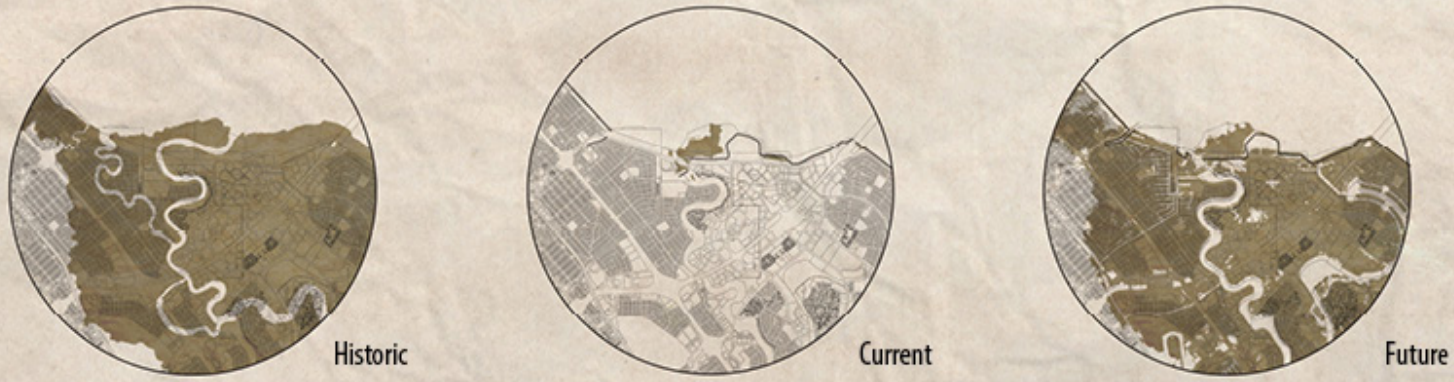

Figure 3: Site Analysis Past, Present, and Future of San Mateo, CA.

uncover what exists under city streets and building foundations and determine how the natural systems worked before they were filled in and confined. This process is particularly important to develop strategies for waterfront adaptation to sea-level rise as the areas that are most prone to flooding are typically built on reclaimed land and filled historical wetlands.

An exploration of urban morphology discloses the transformations of a city over time and describes the phases of development. It is telling to discover where a city was first developed and consider why. Often, the most suitable areas are developed first and vulnerable areas later, although this fact may be hidden through the layering of construction over time. The process of site investigation highlights the fact that not all parts of the city fabric were necessarily designed thoughtfully. There are countless examples of urban development that has been done in a rushed manner, more concerned with the economic aspects of development than the long-term suitability of placemaking through an informed design process. This realization can be liberating and inspire a departure from current urban form.
Mapping the present combines, a collage of the built and natural environment, an experiential and subjective understanding of the landscape, and socio-economic factors. Any design proposal, no matter how audacious, must consider and interface the present condition. While much of the infrastructure in the United States is outdated, questions arise as to how new and innovative designs will coalesce will the old infrastructure to bring back the natural functions of the surrounding ecology. Some of these answers may be found through an analysis of the past historical ecology and urban transformations. In turn, the past may become the future as sea-level rise portends to reclaim the land that has been built on fill.

Projecting the future environment is essential to developing scenario-based strategies that accommodate change. By layering sea-level rise flood levels on the present built environment, we can address vulnerabilities. Urban simulations can in turn forecast future trends in growth, demographics, and economic value. Whether an urban area is thriving in the future or displaced due to climate change events may ultimately be determined by the use of appropriate strategies, which primarily consider the landscape in the design process. This will be particularly true of coastal development, as it inhabits a 


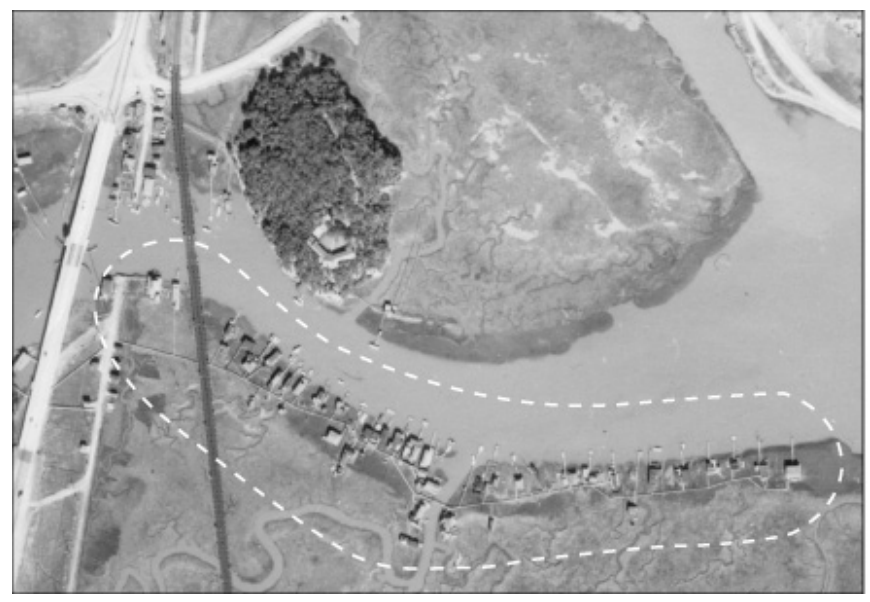

Figure 4: Greenbrae Houseboat Community, Corte Madera, CA; Aerial Photograph 1930 (left), Contemporary Photograph 2012 (right)

contested landscape between land and sea. Whether urbanized waterfronts decide to accommodate, retreat, or protect against sea-level rise and coastal transformations will largely be due in part to the relationship of the present conditions to the past landscape and how this is used to define the future water's edge.

\section{THE PROBLEM WITH DEFINING THE WATER'S EDGE}

The coastline is not a line, but rather a transition zone from water to dry land. This is where terminology and representation play an important role in policy, perception, and practice. The coastline is indeed shown as a line on most maps and depending on the scale this may be an appropriate abstraction. However, when zoomed into an area along the coastline this abstraction becomes deceptive in illustrating the coast as a clean and narrow divide between land and sea. The use of a line to denote the coast does not account for tidal fluctuations and ignores the natural shifting of coastal topography in the form of erosion and migrating beaches caused by storms. The coastline is by nature a continually changing form, which has a varying thicknesses of transitional area based on location, geography, and geology.

The coastline that defines the San Francisco Bay varies by location, but is especially "thick" in the north and south bay. This wide transition zone between high and low tide creates tidal wetlands and has been described as being "halfway worlds between terrestrial and aquatic ecosystems that exhibit some of the characteristics of each." The wetlands can therefore be described as being neither land nor sea, but instead creating a "fuzzy" edge between the two: of mud, plants, and water. A study of the urban morphology of the Bay's shoreline illustrates that it was precisely the width and shallow depth of the tidal wetlands that has presented an opportunity for entrepreneurs to make money off of the land by filling it in for industrial, commercial, and housing development. This, of course, required defining an edge between what was urban

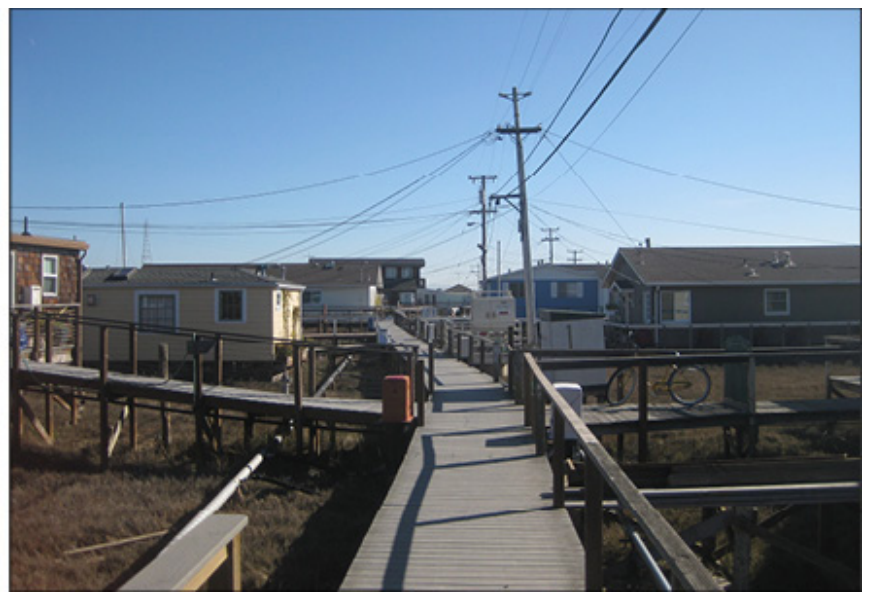

development and what was bay, thus denying the coast its nature by disallowing tidal action and topographic changes that come with storms and sediment.

The creation of a "fixed" urban edge is not without its reasons. The defining of a boundary is essential for the concept of ownership. An edge that is continually changing is perceived as problematic for the protection of ownership and the safety of life, land, and infrastructure. This has resulted in the creation of a numerous sea abatement strategies, from the hardscape bulkhead of San Francisco's downtown waterfront, to the riprap walls surrounding Foster City, and the series of levee fortifications dividing the salt marshes by Union City.

Each of these defined boundaries along the water's edge gives a false sense of permanence to the adjacent development. By layering maps of the past historic tidal wetlands, with present development built reclaimed land, and projected future sea-level rise inundation, it becomes apparent that the Bay waters are coming to claim what has been filled. As sea levels continue to rise, the sense of permanence associated with the hard edge divides from sea abatement protection may gradually change with increased flood events and a corresponding escalation in property insurance rates. By continuing the strategy of creating bigger and better barriers to keep property safe from inundation, this will also result in perpetuating the separation of urban development from the adjacent natural environment.

The misconception of establishing permanence through a continuous urban edge is central to the problem with current development along the waterfront of the Bay and vital to solutions that address the implications of sea-level rise. The incorporation porosity and flux into the urban edge offers opportunities to create more resilient and adaptable cities. By understanding the past landscape conditions, we can better design for the future levels of rising tides in a manner that works with the ecological systems to create a new relationship between built and natural environments along the coastline of the San Francisco Bay. 


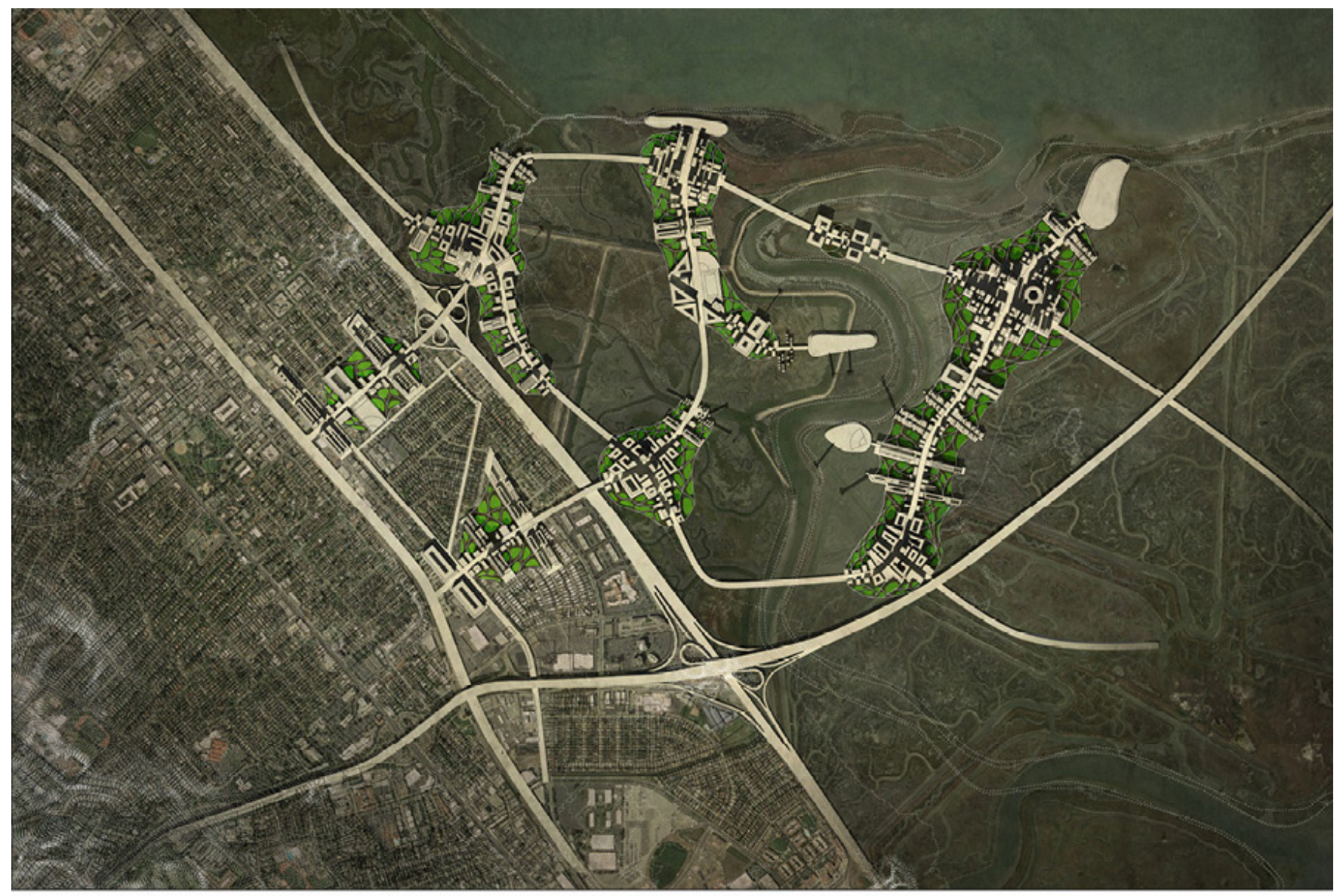

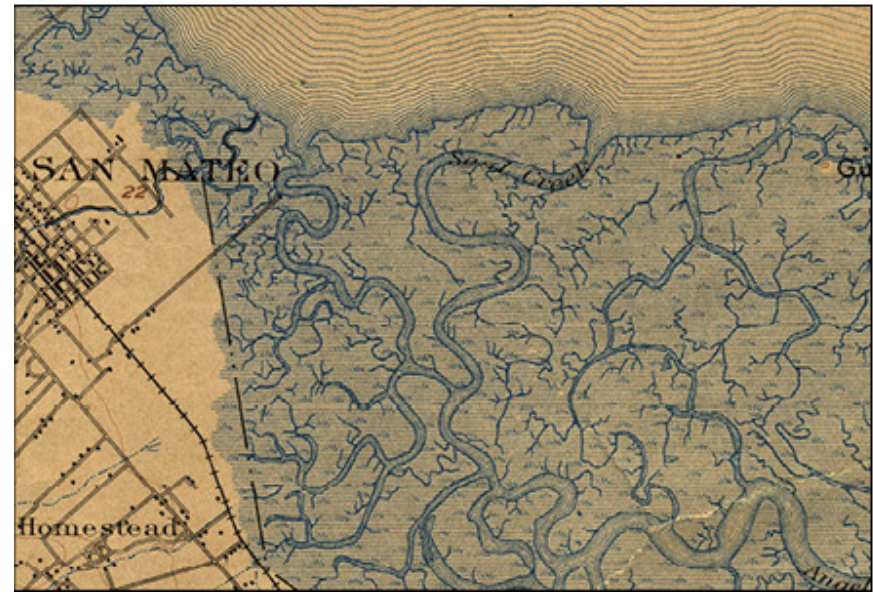

Figure 5 Sea-Level Rise Adaptation and Redevelopment Strategy for San Mateo, CA; Historical Tidal Wetlands 1899 Map (bottom-left), Suitability Buffer of Historical Tidal Waterways (bottom-right), Master Plan at $100 \mathrm{~cm}$ Sea-Level Rise (top).

\section{LIVING SHORELINES}

By defining a fixed urban edge on the waterfront, we doom it to failure. Just as the coast naturally rises and recedes with the tides and changes in form with the wind and rain, the design of the urban waterfront should respond to coastal transformations over time. While the waterfront has historically been a place of maritime commerce and industrial operations, many

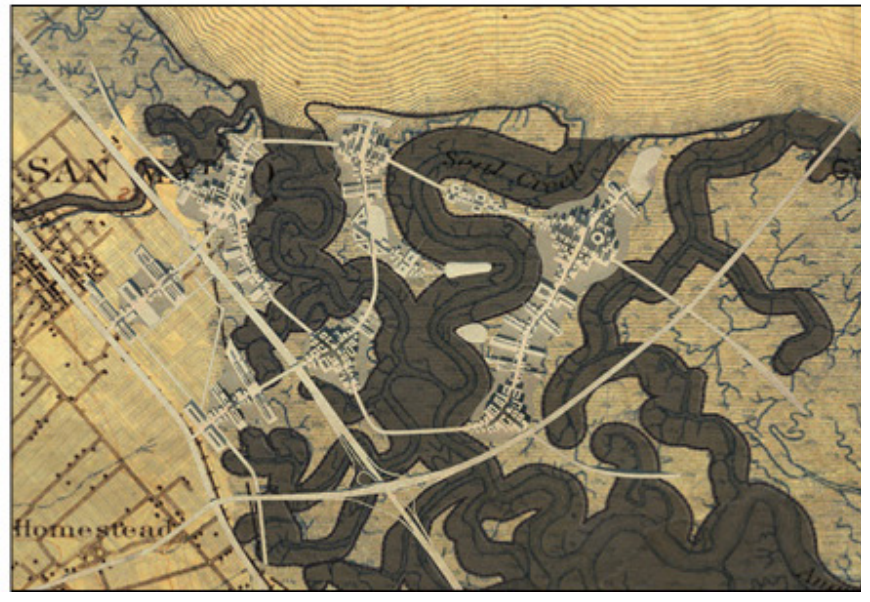

cities around the world have been redeveloping this land to attract private real estate investment and urban growth. This presents an ideal opportunity to create innovative new approaches to urban coastal development that considers the past, present, and future landscape.

Waterfront re-development projects around the world, for the most part, do not include restoration of native habitat or the inclusion of soft-scape in defining a more porous urban edge. As landscape architecture theorist Kristina Hill states, "few examples exist of cities that have tried to bring intertidal or 
sub-tidal habitat into their waterfront designs, in part because the promenade emphasizes a more manicured aesthetic that includes water and the reflections of buildings and boats, but not grassy mudflats that might smell of sulphur at low tide." However, there are some good precedents of cities incorporating strategies to integrate historic wetlands and natural flood basins, such as the Dutch policy to make 'room for river' aimed at increasing the area available for rivers in flood prone areas, the Hammarby-Sjostad district in Stockholm that integrated intertidal wetlands into the urban design to provide corridors for wildlife, and the London Thames Gateway Project that proposes a regional park network intended to detain floodwaters along the tributaries that would also provide recreational and an ecological network.

A small, albeit, excellent example of coastal cohabitation is the Greenbrae houseboat community in Corte Madera, California, which is situated on a tidal wetland on the edge of the San Francisco Bay. Here there is a thriving community coexisting with the surrounding Bay ecosystem. Located between Larkspur Creek and the Corte Madera wetlands, the houseboat community was the first development in the area during the early 1900's, originally built as hunting shacks. It is currently the site of 49 houses and is one of the oldest and best examples of development coexisting on the San Francisco Bay edge without the use of sea abatement structures.

The development is unique in that it contains the linear infrastructure of a single boardwalk running between the buildings, which serve as a sole point of access. Underneath and alongside the boardwalk, all of the infrastructure, including fresh water, electricity, and sewage, are contained in a single linear design. The buildings float with the rising tide or sit on pilings, which allow for tidal action underneath the structure and can be elevated when needed. This was a strong influence for my research and design project titled, "Sea-Level Hi-Rise: or, How I Learned to Stop Worrying and Love Climate Change," where I created a speculative design proposal of dense urban development that could coexist in the tidal wetland area along the San Francisco Bay, while accommodating sea-level rise.

The design for "Sea-Level Hi-Rise" was conceived as a collaborative process with the landscape. By mapping the past, present, and future of the site, I created a managed retreat proposal with different stages of sea-level rise and a resilient redevelopment strategy with a dense urban structure in the tidal wetland area. Similar to the form of the Greenbrae houseboat community, the urban design has a central roadway built on what I call a "finger levee" that contains all of the infrastructure and transportation, with dense development built on piers. The location of development and form of the finger levee are determined by a study of the historic wetlands and a buffering system of tidal waterways that is spaced to enable a healthy Bay ecosystem. The new finger levee development then connects to the existing urban fabric at major infrastructural nodes.
This project represents one example of using site analysis as a design driver, enabling collaboration with the landscape. However, its goal is not to serve as a model, but rather to propose resilient and adaptable waterfront strategies and create a dialog by raising further questions into the way we design our environment. How might we develop new ways to incorporate knowledge of the ecological processes of the natural environment into the design of the built environment, perhaps blurring the distinction between the two? How can we design buildings and cities that are adaptable to climate change and the flux of environmental conditions? Answers to these questions will hopefully lead to urban designs that place more importance on working with the landscape than trying to control or erase it.

\section{CONCLUSION}

By changing the current top-down approach to city making instead to a bottom-up strategy that begins by collaborating with the landscape, we can improve the relationship between the built and natural environment, creating more resilient, adaptable, and unique urban places. This will require expanding the scope of site analysis to more thoroughly integrate with the design process, while incorporating techniques of mapping the past, present, and potential future. As sea levels continue to rise and with storms of increasing severity and frequency, coastal communities will be particularly vulnerable to the affects of climate change. The design of resilient urban waterfronts will require a reframing of the urban boundaries associated with the coastline that focus on working with the ecological functions of the landscape to determine new urban form and infrastructure that demonstrates a place-based suitability. This is not a task for a single discipline, but rather a call for all of the professions concerned with design of the built environment to consider how we can collaborate with the landscape and each other to create better cities. In turn, the problems associated with climate change can instead be reframed as an opportunity to define new and innovative approaches to design the built environment that begins first with the landscape.

\section{ENDNOTES}

1 Carol J. Burns and Andrea Kahn, "Why Site Matters" in Site Matters: Design Concepts, Histories, and Strategies, Burns, Carol J. and Andrea Kahn, eds (New York: Routledge, 2005), $x$.

2 Andrea Kahn, "Defining Urban Sites." in Site Matters: Design Concepts, Histories, and Strategies, Burns, Carol J. and Andrea Kahn, eds (New York: Routledge, 2005), (New York: Routledge, 2005), 286.

3 James Corner, "The Agency of Mapping: Speculation, Critique and Invention," in Mappings, ed. Denis Cosgrove (London: Reaktion Books Ltd., 1999), 216.

4 Luna Leopold, et al., "Baylands Ecosystem Habitat Goals: A Report of Habitat Recommendations / prepared by the San Francisco Bay Area Wetlands Ecosystem Goals Project." (Oakland, CA: San Francisco Estuary Project c/o S.F. Bay Regional Water Quality Control Board, 1999),10.

5 Kristina Hill, "Climate-Resilient Urban Waterfronts." In Climate Adaptation and Flood Risk in Coastal Cities, edited by Jeroen Aerts, Wouter Botzen, Malcolm J. Bowman, Philip J. Ward and Piet Dircke, 123-144. (New York, NY: Earthscan, 2012) 138.

6 "Greenbrae Boardwalk," Hidden Ecologies, August 21, 2006 